Research article

\title{
Genetic variation in insulin-like growth factor signaling genes and breast cancer risk among BRCA1 and BRCA2 carriers
}

\author{
Susan L Neuhausen1, Sean Brummel2 ${ }^{2}$ Yuan Chun Ding1, Christian F Singer ${ }^{3}$, Georg Pfeiler ${ }^{3}$, \\ Henry T Lynch ${ }^{4}$, Katherine L Nathanson ${ }^{5}$, Timothy R Rebbeck 6 , Judy E Garber7, Fergus Couch ${ }^{8}$, \\ Jeffrey Weitzel ${ }^{9}$, Steven A Narod ${ }^{10}$, Patricia A Ganz ${ }^{11}$, Mary B Daly ${ }^{12}$, Andrew K Godwin ${ }^{13}$, \\ Claudine Isaacs ${ }^{14}$, Olufunmilayo I Olopade ${ }^{15}$, Gail Tomlinson ${ }^{16}$, Wendy S Rubinstein ${ }^{17}$, \\ Nadine Tung ${ }^{18}$, Joanne L Blum ${ }^{19}$ and Daniel L Gillen ${ }^{1,2}$
}

\author{
1Department of Epidemiology, University of California Irvine, 224 Irvine Hall, Irvine, CA 92697, USA \\ 2Department of Statistics, University of California Irvine, 2226 Bren Hall, Irvine, CA 92697 USA \\ 3Division of Special Gynecology, Department of Obstetrics and Gynaecology, Medical University of Vienna, Waehringer Guertel 18-20, 1090 Vienna, \\ Austria \\ ${ }^{4}$ Department of Preventive Medicine and Public Health, Creighton University School of Medicine, 2500 California Plaza, Omaha, NE 68182, USA \\ 5Department of Medicine, Medical Genetics, University of Pennsylvania School of Medicine, 351 BRB 2/3, 421 Curie Blvd, Philadelphia, PA 19104, \\ USA \\ ${ }^{6}$ Department of Biostatistics and Epidemiology Abramson Cancer Center University of Pennsylvania School of Medicine, 217 Blockley Hall, 423 \\ Guardian Drive, Philadelphia, PA 19104, USA \\ ${ }^{7}$ Department of Adult Oncology, Dana Farber Cancer Institute, 44 Binney Street, Boston, MA 02115, USA \\ 8Mayo Department of Laboratory Medicine and Pathology, Mayo Clinic, 200 First Street SW, Rochester, MN 55905, USA \\ 9Division of Clinical Cancer Genetics, Department of Population Sciences, City of Hope National Medical Center, 1500 East Duarte Road, Duarte, \\ CA 91010, USA \\ 10Women's College Research Institute, Women's College Hospital, 790 Bay Street, 7th Floor, Toronto, ON M5G 1N8, Canada \\ 11 UCLA Schools of Medicine and Public Health Division of Cancer Prevention \& Control Research, Jonsson Comprehensive Cancer Center, 650 \\ Charles Young Drive South, Room A2-125 CHS, Los Angeles, CA 90095-6900, USA \\ ${ }^{12}$ Department of Clinical Genetics, Fox Chase Cancer Center, 333 Cottman Avenue, Philadelphia, PA 19111, USA \\ ${ }_{13}^{13}$ Department of Medical Oncology, Fox Chase Cancer Center, 333 Cottman Avenue, Philadelphia, PA 19111, USA \\ ${ }^{14}$ Department of Medicine and Oncology, Georgetown University, 3800 Reservoir Road, NW, Washington, DC 20007, USA \\ 15Departments of Medicine and Human Genetics, University of Chicago, 5841 S. Maryland Avenue, MC2115, Chicago, IL 60637, USA \\ ${ }^{16}$ Division of Pediatric Hematology Oncology, University of Texas Health Science Center at San Antonio, 7703 Floyd Curl Drive, San Antonio, TX \\ 78229-3901, USA \\ 17Department of Medicine, NorthShore University Health System, 1000 Central Street, Suite 620, Evanston, IL 60201, USA \\ ${ }^{18}$ Department of Medical Oncology, Beth Israel Deaconess Medical Center, 330 Brookline Avenue, Boston, MA 02215, USA \\ ${ }^{19}$ Department of Oncology, Baylor University Medical Center, 3535 Worth St. Suite 600, Dallas, TX 75246, USA
}

Corresponding author: Susan L Neuhausen, sneuhaus@uci.edu

Received: 13 Mar 2009 Revisions requested: 5 Jun 2009 Revisions received: 16 Sep 2009 Accepted: 20 Oct 2009 Published: 20 Oct 2009

Breast Cancer Research 2009, 11:R76 (doi:10.1186/bcr2414)

This article is online at: http://breast-cancer-research.com/content/11/5/R76

(c) 2009 Neuhausen; licensee BioMed Central Ltd.

This is an open access article distributed under the terms of the Creative Commons Attribution License (http://creativecommons.org/licenses/by/2.0), which permits unrestricted use, distribution, and reproduction in any medium, provided the original work is properly cited.

\section{Abstract}

Introduction Women who carry mutations in BRCA1 and $B R C A 2$ have a substantially increased risk of developing breast cancer as compared with the general population. However, risk estimates range from 20 to $80 \%$, suggesting the presence of genetic and/or environmental risk modifiers. Based on extensive in vivo and in vitro studies, one important pathway for breast cancer pathogenesis may be the insulin-like growth factor (IGF) signaling pathway, which regulates both cellular proliferation and apoptosis. BRCA1 has been shown to directly interact with
IGF signaling such that variants in this pathway may modify risk of cancer in women carrying BRCA mutations. In this study, we investigate the association of variants in genes involved in IGF signaling and risk of breast cancer in women who carry deleterious $B R C A 1$ and $B R C A 2$ mutations.

Methods $A$ cohort of 1,665 adult, female mutation carriers, including 1,122 BRCA1 carriers (433 cases) and 543 BRCA2 carriers (238 cases) were genotyped for SNPs in IGF1, IGF1 receptor (IGF1R), IGF1 binding protein (IGFBP1, IGFBP2,

Cl: confidence interval; $D^{\prime}$ : pairwise linkage disequilibrium coefficient; HR: hazard ratio; IGF: insulin-like growth factor; IGF1R: insulin-like growth factor-1 receptor; IGFBP: insulin-like growth factor binding protein; IRS1: insulin-like growth factor receptor substrate 1; LD: linkage disequilibrium; PCR: polymerase chain reaction; SNP: single nucleotide polymorphism. 
IGFBP5), and IGF receptor substrate 1 (IRS1). Cox proportional hazards regression was used to model time from birth to diagnosis of breast cancer for BRCA1 and BRCA2 carriers separately. For linkage disequilibrium (LD) blocks with multiple SNPs, an additive genetic model was assumed; and for single SNP analyses, no additivity assumptions were made.

Results Among BRCA1 carriers, significant associations were found between risk of breast cancer and LD blocks in IGF1R (global $P=0.011$ for LD block 2 and global $P=0.012$ for LD block 11). Among BRCA2 carriers, an LD block in IGFBP2 (global $P=0.0145$ ) was found to be associated with the time to breast cancer diagnosis. No significant LD block associations were found for the other investigated genes among $B R C A 1$ and BRCA2 carriers.

Conclusions This is the first study to investigate the role of genetic variation in IGF signaling and breast cancer risk in women carrying deleterious mutations in BRCA1 and BRCA2. We identified significant associations in variants in IGF1R and IRS1 in BRCA1 carriers and in IGFBP2 in BRCA2 carriers. Although there is known to be interaction of $B R C A 1$ and IGF signaling, further replication and identification of causal mechanisms are needed to better understand these associations.

\section{Introduction}

Women who carry mutations in the BRCA1 and BRCA2 genes have a substantially increased risk of developing breast cancer and ovarian cancers as compared with the general population. Estimates of the age-specific risk attributable to mutations at these loci vary depending on the ascertainment scheme. The cumulative risks of breast cancer by age 70 were estimated to be $65 \%$ and $45 \%$ for $B R C A 1$ and BRCA2 mutation carriers, respectively, in a meta-analysis of populationbased studies [1] - as compared with 56 to $80 \%$ for BRCA1 and BRCA2 mutation carriers, respectively, in analyses based on families with multiple affected individuals [2-5].

Among $B R C A 1$ and $B R C A 2$ mutation carriers, there is considerable variability in both the age at diagnosis and the incidence of breast and ovarian cancers, even among women who carry the same $B R C A 1$ and $B R C A 2$ mutation [6-8]. These risk estimates not only show that such women are at extremely high risk for developing breast cancer, but also illustrate that there is great variability in the time to breast cancer diagnosis among carriers. These observations are consistent with the hypothesis that the breast cancer risk in mutation carriers is modified by other genetic and/or environmental factors. There are published reports of genetic modifiers of cancer risk in mutation carriers (for example, variants in $A I B 1$ in $B R C A 1$; variants in RAD51, FGFR2 and MAP3K1 in BRCA2; and variants in TNRC9 in BRCA1 and BRCA2) [9-13].

One important pathway for cancer pathogenesis may be the insulin-like growth factor (IGF) signaling pathway, as it regulates both cellular proliferation and apoptosis. Extensive evidence from in vivo and in vitro model systems and human studies (reviewed in [14-16]) supports a major role for the IGF1 signaling pathway in breast cancer pathogenesis. Mammographic density, a strong risk factor for breast cancer, has been positively associated with the ratio of IGF1 to insulin-like growth factor binding protein (IGFBP)-3 in premenopausal women [17], and has been shown to modify the breast cancer risks in BRCA1 and BRCA2 mutation carriers [18]. BRCA1 has been shown to directly affect IGF1 signaling. In multiple experimental systems, including primary mammary tumors, cul- tured human cells, and Brca1-deficient mice, Shukla and colleagues showed that BRCA1 deficiency resulted in increased expression of insulin-like growth factor receptor substrate 1 (IRS1), insulin-like growth factor-1 receptor (IGF1R), IGFBP2, and increased levels of serum IGF1 [19]. In another study investigating IGF1R levels in breast tumors, there were significantly higher levels of IGF1R in tumors from BRCA1 mutation carriers as compared with noncarriers [20].

We hypothesized that genetic variation in IGF signaling will modify risk of breast cancer in women carrying deleterious mutations in BRCA1 and BRCA2. In the present study, we focused on investigating the association of variants in IGF1, IGFBP1, IGFBP2, IGFBP5, IGF1R, and IRS1 as potential disease modifiers in mutation carriers of $B R C A 1$ and $B R C A 2$.

\section{Materials and methods Participants}

Women with germline, deleterious mutations in BRCA1 and $B R C A 2$ were identified in 14 centers in the US, one center in Canada, and one center in Austria - including Baylor University Medical Center - Dallas, Beth Israel in Boston, City of Hope, Creighton University, Dana Farber, Fox Chase Cancer Center, Georgetown University, the Mayo Clinic, Medical University of Vienna, North Shore University Health System in Chicago, University of California, Los Angeles, University of California, Irvine, University of Chicago, University of Pennsylvania, and Women's College Hospital. The majority of subjects were recruited from the Medical University in Vienna, Creighton University in Nebraska, the University of Pennsylvania, and the University of California Irvine (previously at the University of Utah). All centers are part of the Modifiers and Genetics in Cancer consortium. All participants were enrolled under Institutional Review Boards or ethics committee approval at each participating site.

Women were participating in research studies or were either physician or self-referred to risk evaluation clinics for genetic testing, generally because of a strong family history of breast cancer and/or ovarian cancer. The current study is composed of a total of 1,665 adult, female mutation carriers, including 
1,122 BRCA 1 carriers ( 433 cases and 689 controls) and 543 $B R C A 2$ carriers (238 cases and 305 controls). The BRCA1 and $B R C A 2$ mutation status of all subjects was confirmed by direct mutation testing, with full informed consent under protocols approved by the human subjects review boards at each institution.

Women were eligible for entry into the study cohort if they tested positive for a known deleterious mutation in BRCA1 or BRCA2. Women with BRCA1 and BRCA2 variants of unknown functional significance were excluded. Women were excluded if they were missing information on year of birth, parity, menopausal status, and oral contraceptive use, or had been diagnosed with cancer more than 3 years prior to study entry. Information about invasive breast cancer, ovarian cancer, prophylactic mastectomy and prophylactic oophorectomy was obtained from medical records, and information on reproductive history and lifestyle habits was obtained by questionnaire.

\section{SNP genotyping}

The 47 SNPs had been selected and genotyped in a previous case-control study of African-American women. Briefly, a minimal set of informative SNPs (tagging SNPs) had been chosen across each gene to mark the common genetic variation and to minimize the genotyping costs. Tagging SNP sets were selected using the TagSNPs program [21] from genotype data, downloaded directly from the National Institute of Environmental Health Sciences Environmental Genome Project [22]. For the data available at the time, it was not possible to select tagging SNPs for just a Caucasian population.

Genotyping was performed by the MGB Taqman probe Assay from Applied Biosystems Inc. (Foster City, CA USA) or the MGB Eclipse ${ }^{\mathrm{TM}}$ probe assay from Nanogen Inc. (San Diego, CA USA) for all SNPs. Primer and probe sequences are available from the authors on request.

Specifically, for the MGB Taqman probe assays, the reaction mix in a final volume of $5 \mu$ included $10 \mathrm{ng}$ genomic DNA, 4.5 pmol each primer, $1.25 \mathrm{pmol}$ each probe, $1 \times$ PCR reaction buffer (Qiagen, Gaithersburg, MD USA), $2 \times$ Q solution (Qiagen), 500 pmol dNTP, and 0.15 units Qiagen DNA polymerase. PCR cycling included 55 cycles of a two-step PCR $\left(95^{\circ} \mathrm{C}\right.$ for 15 seconds, and $60^{\circ} \mathrm{C}$ for 1 minute) after an initial 2 minutes at $95^{\circ} \mathrm{C}$. PCR plates were read on an ABI PRISM 7900 $\mathrm{HT}$ instrument for genotype assignment (Applied Biosystems Inc.).

Specifically, for the MGB Eclipse ${ }^{\mathrm{TM}}$ probe assays, the reaction mix in a final volume of $5 \mu$ included $10 \mathrm{ng}$ genomic DNA, 0.5 pmol limiting primer, 5 to $10 \mathrm{pmol}$ excess primer, 1 pmol each probe, $1 \times$ PCR reaction buffer (Qiagen), $2 \times$ Q solution (Qiagen), $500 \mathrm{pmol}$ dNTP, and 0.15 units Qiagen DNA polymerase. PCR cycling included 55 cycles of a three-step PCR $\left(95^{\circ} \mathrm{C}\right.$ for 10 seconds, $58^{\circ} \mathrm{C}$ for 20 seconds and $72^{\circ} \mathrm{C}$ for 20 seconds) after an initial 2 minutes at $95^{\circ} \mathrm{C}$.

After completion of PCR, endpoint dissociation melting curves were generated on the ABI PRISM $7900 \mathrm{HT}$ instrument by monitoring the fluorescence while heating the reactions from $30^{\circ} \mathrm{C}$ to $80^{\circ} \mathrm{C}$ at a $10 \%$ rate. An EclipseMeltMacro_v2.328 program (Nanogen Inc., San Diego, CA USA) was employed to assign the genotype from the dissociation curve data. Duplicates of 22 DNA samples and water controls were genotyped for quality control. The laboratory technician was blinded as to whether samples were duplicates, cases, or controls. The order of the DNA samples on 384-well plates was randomized in order to ensure balance in study conditions across covariates. Genotyping call rates ranged from $95 \%$ to $99 \%$ and duplicate concordance rates were higher than $99 \%$.

\section{Determination of linkage disequilibrium blocks}

We recalculated the linkage disequilibrium (LD) blocks for this study, primarily because we wanted the LD groups to reflect this predominantly non-Hispanic Caucasian cohort rather than the mixed sample from which the tagging SNPs were originally identified. SNPs were grouped according to their adjacent pairwise LD coefficient $\left(D^{\prime}\right)$. The coefficient was computed between all adjacent marker pairs within each candidate gene. In order to account for within-family correlation, multiple outputation [23] was used to estimate $D^{\prime}$. In this case, a single member from each family was randomly sampled to create a single bootstrap sample, from which $D^{\prime}$ was computed. This process was repeated to obtain 200 bootstrap samples, yielding an empirical distribution of $D^{\prime}$. An LD block was defined as a set of contiguous SNPs having $D^{\prime}$ values exceeding 0.90 between each contiguous pair of SNPs. The boundary of an LD block would be defined by a marker pair with $D^{\prime} \leq 0.9$. The LD blocks for the SNPs within each gene are shown in Additional data file 1.

\section{Statistical analysis}

Breast cancer rates were calculated as the observed number of breast cancers per total patient time at risk, and were standardized to the age distribution of the study cohort at the time of interview [24]. Subjects were considered at risk for breast cancer from birth until the first occurrence of breast cancer diagnosis, death, or loss to follow-up. In addition, subjects were censored in the event that they underwent a bilateral prophylactic surgery of the breasts more than 1 year preceding the diagnosis of breast cancer. Bilateral prophylactic surgery of the breasts occurring within 1 year of breast cancer was considered an event in order to avoid potential biases resulting from informative censoring.

Covariates that vary with time (ovarian cancer and prophylactic ovarian surgery) were treated as time dependent in the calculation of rates. A subject who was diagnosed with ovarian cancer therefore contributed time at risk in the non-ovarian cancer 
Table 1

Participant characteristics and incidence of breast cancer diagnosis by BRCA status

\begin{tabular}{|c|c|c|c|c|c|c|}
\hline \multirow[b]{2}{*}{ Characteristic } & \multicolumn{3}{|c|}{ BRCA1 } & \multicolumn{3}{|c|}{$B R C A 2$} \\
\hline & $n$ & Cases & Incidence rate ${ }^{a}$ & $n$ & Cases & Incidence rate ${ }^{a}$ \\
\hline Total & 1,122 & 433 & $26.94(19.79,34.10)$ & 543 & 238 & $25.03(18.71,31.36)$ \\
\hline \multicolumn{7}{|l|}{ Race $^{b}$} \\
\hline Caucasian (non-Jewish, non-Hispanic) & 774 & 283 & $26.72(19.58,33.86)$ & 381 & 176 & $27.70(20.63,34.77)$ \\
\hline African American & 29 & 14 & $39.37(28.13,50.61)$ & 13 & 6 & $25.28(18.47,32.09)$ \\
\hline Jewish & 245 & 98 & $24.08(17.95,30.22)$ & 119 & 43 & $17.39(13.19,21.60)$ \\
\hline Caucasian Hispanic & 35 & 17 & $43.97(30.46,57.47)$ & 9 & 5 & $33.07(22.50,43.65)$ \\
\hline Other & 31 & 16 & $38.66(28.28,49.05)$ & 19 & 6 & $20.68(15.61,25.74)$ \\
\hline \multicolumn{7}{|l|}{ Ovarian cancer } \\
\hline Yes & 128 & 26 & $20.86(11.70,30.01)$ & 30 & 5 & $18.90(8.84,28.96)$ \\
\hline No & 994 & 407 & $27.78(20.46,35.10)$ & 513 & 233 & $25.43(19.10,31.77)$ \\
\hline \multicolumn{7}{|l|}{ Prophylactic ovarian surgery } \\
\hline Yes before breast cancer & 282 & 44 & $24.88(17.53,32.23)$ & 108 & 18 & $27.64(19.07,36.21)$ \\
\hline Yes after breast cancer & 167 & 167 & -- & 99 & 99 & -- \\
\hline No bilateral prophylactic oophorectomy & 671 & 221 & $28.07(20.72,35.42)$ & 336 & 121 & $25.29(18.93,31.64)$ \\
\hline \multicolumn{7}{|l|}{ Clinic Site } \\
\hline Medical University Vienna & 204 & 84 & $39.26(29.31,49.21)$ & 62 & 37 & $28.19(20.83,35.55)$ \\
\hline Beth Israel & 8 & 4 & $30.58(22.39,38.76)$ & 15 & 6 & $125.51(35.71,215.31)$ \\
\hline Baylor University Medical Center --Dallas & 14 & 10 & $69.46(50.29,88.63)$ & 1 & 1 & $14.59(10.21,18.97)$ \\
\hline City of Hope & 56 & 25 & $43.30(31.79,54.81)$ & 28 & 17 & $54.17(40.17,68.18)$ \\
\hline Creighton & 155 & 65 & $28.49(21.39,35.59)$ & 40 & 23 & $55.87(42.83,68.91)$ \\
\hline Dana Farber & 88 & 41 & $36.22(27.27,45.18)$ & 32 & 11 & $27.20(21.04,33.37)$ \\
\hline NorthShore University Health System & 35 & 16 & $26.55(19.62,33.47)$ & 21 & 9 & $17.77(13.57,21.97)$ \\
\hline Fox Chase Cancer Center & 40 & 10 & $14.41(9.97,18.86)$ & 28 & 9 & $18.18(13.32,23.04)$ \\
\hline Georgetown University & 42 & 13 & $21.35(16.23,26.47)$ & 16 & 3 & $21.64(16.24,27.05)$ \\
\hline University of California, Los Angeles & 43 & 18 & $36.95(25.09,48.81)$ & 17 & 7 & $13.62(10.03,17.21)$ \\
\hline Mayo Clinic & 60 & 17 & $18.57(14.53,22.61)$ & 31 & 10 & $30.38(24.01,36.75)$ \\
\hline University of Texas Health Science Center at San Antonio & 35 & 17 & $40.18(27.33,53.02)$ & 32 & 13 & $11.67(9.00,14.34)$ \\
\hline University of Chicago & 34 & 15 & $52.84(36.66,69.02)$ & 18 & 9 & $18.73(14.47,22.98)$ \\
\hline University of Pennsylvania & 147 & 56 & $24.08(17.37,30.78)$ & 92 & 44 & $51.62(43.58,59.66)$ \\
\hline University of Utahc & 115 & 30 & $14.85(10.70,19.00)$ & 87 & 27 & $27.54(19.36,35.72)$ \\
\hline Women's College Hospital, Toronto & 46 & 12 & $16.24(11.72,20.76)$ & 23 & 12 & $44.56(33.11,56.02)$ \\
\hline $\mathrm{Age}^{d}$ & & & $44.7 \pm 11.2$ & & & $48.1 \pm 13$ \\
\hline
\end{tabular}

aData presented as incidence per 1,000 women per year (95\% confidence interval). Rates have been externally standardized to the age distribution of the study cohort at the time of genetic testing. bFive subjects missing race information. cNow at University of California, Irvine. dData presented as mean \pm standard deviation.

group prior to the diagnosis and then time at risk in the ovarian cancer group following the diagnosis. Because subjects were ascertained primarily from high-risk clinics, there was an over- sampling of cases. In order to account for potential bias in cumulative risk estimates due to nonrandom sampling from the general population, Kaplan-Meier estimates of the cumulative 
Figure 1

\section{Weighted Kaplan Meier Plot}

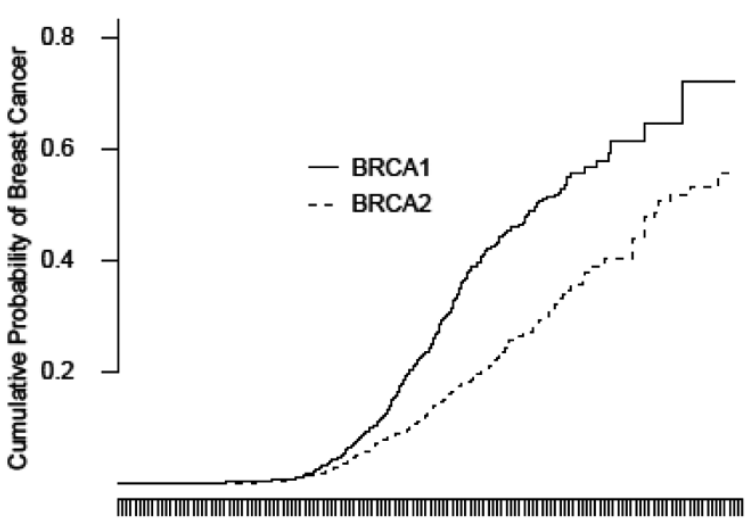

$\begin{array}{llllllllll}10.0 & 17.5 & 25.0 & 32.5 & 40.0 & 47.5 & 55.0 & 62.5 & 70.0 & 77.5\end{array}$

Age

$\begin{array}{lcccccccc}\text { BRCA1 } & 1122(0) & 1118(0) & 962(34) & 573(233) & 219(379) & 63(426) & 19(432) & 3(433) \\ \text { BRCA2 } & 543(0) & 541(0) & 485(11) & 341(86) & 164(179) & 58(224) & 24(234) & 6(238) \\ & & & & & & & & \\ \text { Total } & 1665(0) & 1659(0) & 1467(45) & 914(319) & 383(558) & 121(650) & 43(666) & 9(671)\end{array}$

Kaplan-Meier estimates of the cumulative probability of breast cancer diagnosis by BRCA status. Statistics in the lower portion of the plot represent the number of patients at risk (cumulative number of diagnoses) at each decade of life, ranging from 20 to 80 years. Estimates are weighted to account for oversampling of cases to controls [1].

probability of breast cancer diagnosis were computed using age-specific sampling weights for cases and controls. Sampling weights were obtained from Antoniou and colleagues [1].

Cox proportional hazards regression was used to model the time from birth to diagnosis of breast cancer. In this model, the hazard or instantaneous probability of breast cancer diagnosis is modeled as a function of the predictor covariates. The relative risk or hazard ratio $(\mathrm{HR})$ is then interpreted for each covariate as the proportionate change in the instantaneous probability of diagnosis for two individuals, differing only by a single unit of that covariate. When analyzing LD blocks with multiple SNPs, an additive haplotype effect was assumed where the most common haplotype was used as the referent group for comparisons. When an LD block consisted of a single SNP, however, a general genetic model making no additivity assumption was used. In order to account for phase uncertainty in haplotype analysis, we used a two-step approximation to the semiparametric maximum likelihood estimator of Lin and Zeng [25]. Using this method, the expectation-maximization algorithm was used to compute posterior estimates of the probability of all potential haplotypes for a subject given their known genotype, and these probabilities were used to weight the individual's contribution to the partial likelihood. A similar approach has previously been applied to logistic regression models for analyzing case-control data and was shown to provide robust inference for relatively common haplotypes with little phase ambiguity [26]. In order to account for hierarchical clustering at the individual level (multiple records per individual were analyzed according to the number of potential diplotypes consistent with the individual's genotype) and at the family level (matched controls were often selected from the family of a case), the sandwich estimator of Lin and Wei [27] was used in combination with multiple outputation [23] to obtain robust variance estimates of haplotype associations.

All estimates were adjusted for birth cohort (to account for frequency matching of cases and controls), race/ethnicity, parity, and region of center (North American (US) vs. European). Ashkenazi Jewish individuals were considered a separate ethnicity because the carriers only had one of three founder mutations. Parity, prophylactic oophorectomy, and ovarian cancer status were treated as time-dependent covariates in the analysis, with these covariates updated at the time of childbirth. Beyond adjustment for birth cohort, no additional weighting for selection was employed. For LD blocks exhibiting significant associations with the time to breast cancer diagnosis, secondary analyses of individual SNPs making up the LD block were conducted. For all analyses, the proportional hazards assumption was examined by considering multiplicative interactions between each haplotype (or SNP) of interest and (log-transformed) time. No significant departures from the proportional hazards assumption were observed.

In total, the current analysis involves testing of 48 LD blocks, which is likely to result in an inflation of the family-wise type I error rate for the study if unadjusted critical values are used for assessing LD block significance. Noting that this analysis represents a first-stage in identifying variants in the IGF pathway that are associated with time to breast cancer diagnosis, we sought to control the family-wise type error rate at $15 \%$ in order to minimize the type II error rate, limiting the possibility of ruling out potentially important LD blocks from future investigation. Simulation was used to estimate the family-wise type I error rate, assuming a correlation of 0.75 across tests was assumed. Based upon 100,000 simulations it was estimated that an adjusted $P$ value of 0.016 on any individual LD block test would result in a family-wise type I error rate of $15 \%$ for the study. An adjusted $P<0.016$ was interpreted as a significant association.

\section{Results}

The characteristics of the cases and the sites, and the observed incidence rate (per 1,000 women per year) of breast cancer diagnosis stratified by BRCA status are presented in Table 1 . The presented rates have been externally standardized to the age distribution of the study cohort at the time of genetic testing. The study included 1,222 BRCA1 carriers (433 diagnosed with breast cancer) and 543 BRCA2 carriers (238 diagnosed with breast cancer). The age-standardized 


\section{BRCA1}

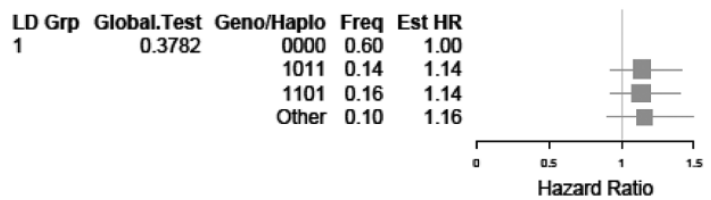

$\underline{B R C A 2}$

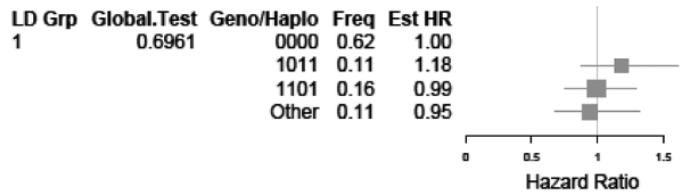

(a) IGFBP1

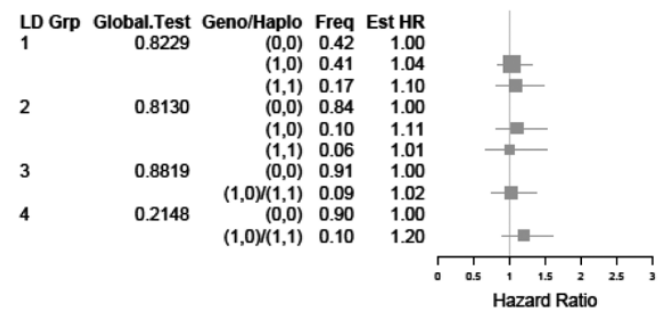

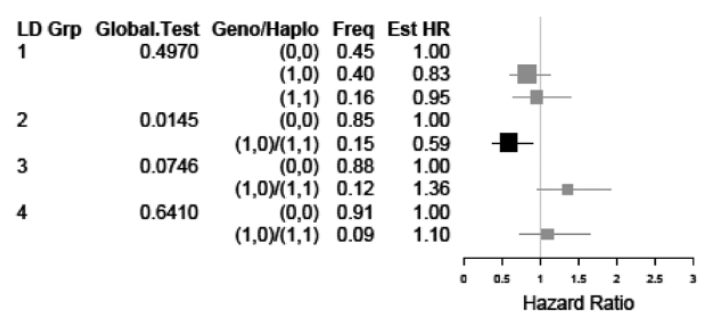

(b) IGFBP2

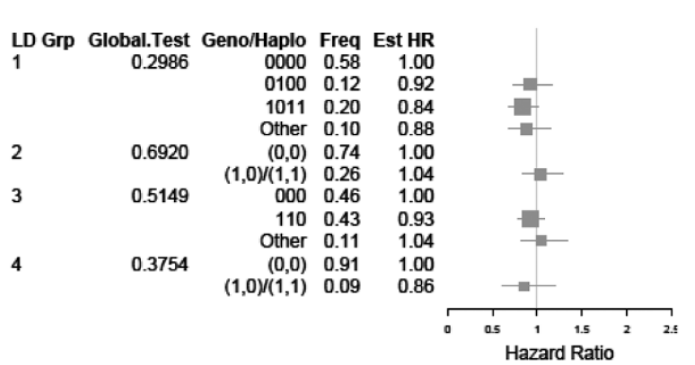

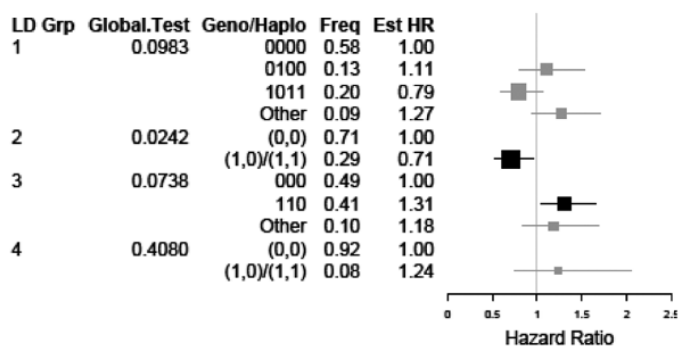

(c) IGFBP5

Haplotype presence for insulin-like growth factor binding proteins. Estimated hazard ratios (Est HR) associated with haplotype presence for (a) insulin-like growth factor binding protein (IGFBP)-1, (b) IGFBP2, and (c) IGFBP5. Linkage blocks were defined as pairwise linkage disequilibrium coefficient $D^{\prime} \geq 0.90$. Estimates were stratified by BRCA status (left column, BRCA1; right column, BRCA2) and adjusted for birth cohort and ethnicity as well as first pregnancy, prophylactic oophorectomy, and diagnosis of ovarian cancer as time-dependent covariates. LD Grp, linkage disequilibrium group; Geno/Haplo, genotype/haplotype; Freq, frequency.

incidence rate of breast cancer diagnosis was estimated to be 26.94 per 1,000 per year in BRCA1 carriers (95\% confidence interval $(\mathrm{Cl})=19.79,34.10)$ compared with 25.03 per 1,000 per year in BRCA2 carriers $(95 \% \mathrm{Cl}=18.71,31.36)$. The majority of study subjects in both strata were White Caucasian (non-Jewish, non-Hispanic). Of the study subjects, 9.5\% underwent bilateral prophylactic mastectomy (107/1,122 among $B R C A 1$ carriers and 40/543 among BRCA2 carriers) and $39.4 \%$ underwent prophylactic bilateral salpingooophorectomy (449/1,122 among BRCA1 carriers and 207/ 543 among $B R C A 2$ carriers). Figure 1 shows the estimated cumulative probabilities of breast cancer diagnosis in BRCA1 and BRCA2 carriers observed in the study. The median age at diagnosis was estimated to be 57.0 years $(95 \% \mathrm{Cl}=54.1$,
62.2) among $B R C A 1$ carriers and was 70.5 years $(95 \% \mathrm{Cl}=$ 67.7, INF) among BRCA2 carriers.

\section{IGF binding proteins IGFBP1, IGFBP2, and IGFBP5}

Figure 2 presents the estimated HR for time to diagnosis by LD block within each of the IGFBPs, and the BRCA status after adjustment for covariates (described in Materials and methods). For BRCA1 carriers, no significant associations were observed for the three IGF binding genes. Among BRCA2 carriers, one LD block in IGFBP2 showed significance in the hazard for diagnosis. For IGFBP2 LD block 2 (defined by a single SNP rs9341134), women with at least one variant allele were estimated to experience a $41 \%$ lower risk of diagnosis when compared with women with no variant 
Figure 3

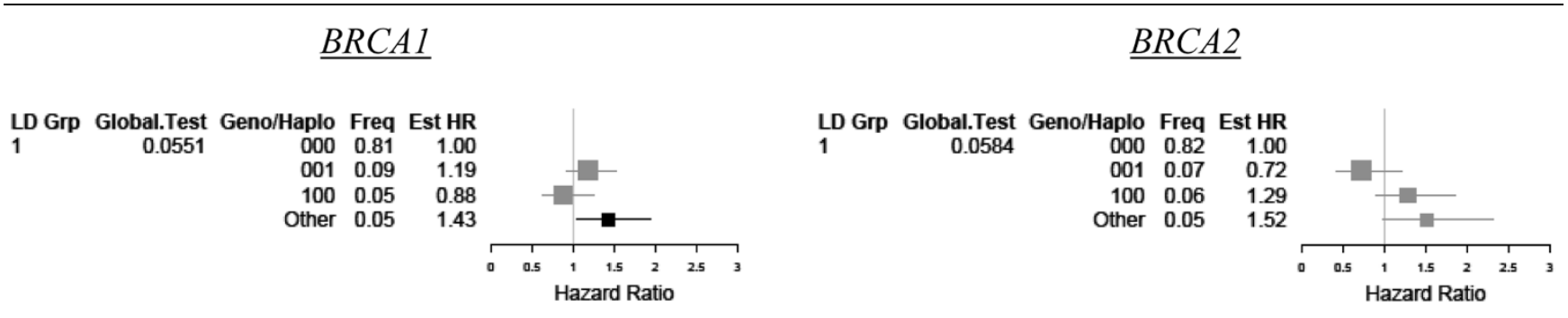

(a) IRS1
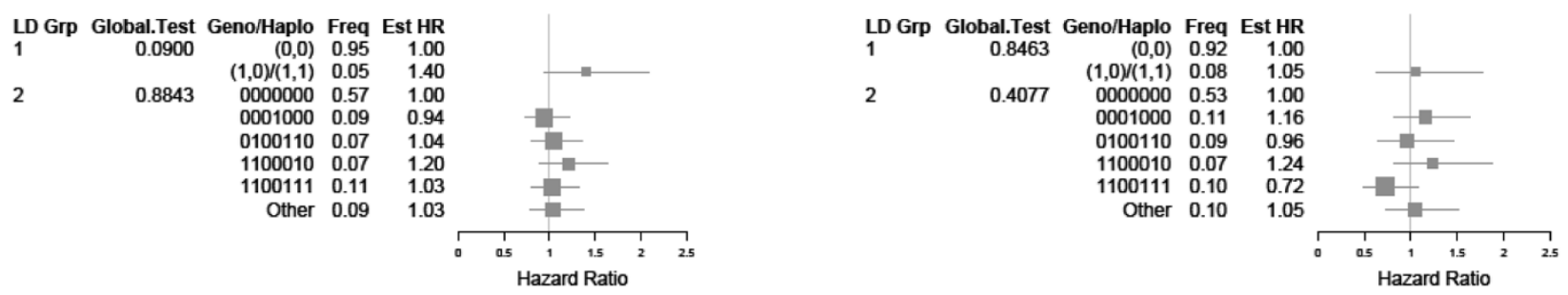

(b) IGF1

Haplotype presence for insulin-like growth factor receptor substrate 1 and insulin-like growth factor 1. Estimated hazard ratios (Est HR) associated with haplotype presence for (a) insulin-like growth factor receptor substrate 1 (IRS1) and (b) insulin-like growth factor 1 (IGF1). Linkage blocks were defined as in Figure 2 (pairwise linkage disequilibrium coefficient $D^{\prime} \geq 0.90$ ). Estimates were stratified by BRCA status (left column, BRCA1; right column, BRCA2) and adjusted for birth cohort and ethnicity as well as first pregnancy, prophylactic oophorectomy, and diagnosis of ovarian cancer as time-dependent covariates. LD Grp, linkage disequilibrium group; Geno/Haplo, genotype/haplotype; Freq, frequency.

alleles $(\mathrm{HR}=0.59 ; 95 \% \mathrm{Cl}=0.39,0.90 ;$ unadjusted global $P$ $=0.0145$ ). For IGFBP5 LD block 2 (defined by a single SNP rs2241193), women with at least one variant allele were estimated to experience a $29 \%$ lower risk of diagnosis when compared with women with no variant alleles $(\mathrm{HR}=0.71 ; 95 \% \mathrm{Cl}$ $=0.53,0.96$; unadjusted global $P=0.0242$ ).

\section{Insulin-like growth factor receptor substrate 1 and insulin-like growth factor 1}

Estimated HRs for the haplotypes of IRS1 are shown in Figure 3a. Among BRCA1 carriers, the global LD block test for IRS1 was not significant (unadjusted global $P=0.0551$ ). Relative to the referent haplotype, however, individuals with haplotypes homozygous for the common variant (excluding haplotypes 001 and 100) were estimated to have a $43 \%(\mathrm{Cl}=1.06,1.95$; $P=0.02$ ) higher risk of breast cancer diagnosis.

We then investigated the HRs for the three SNPs within the LD block to determine whether the observed haplotype associations were attributable to particular SNPs (Table 2). For SNPs rs13306465 and rs1801123, individuals carrying at least one variant allele experienced a $44 \%(\mathrm{HR}=1.44 ; 95 \%$ $\mathrm{Cl}=1.07,1.94 ;$ unadjusted $P=0.0165)$ and $37 \%(\mathrm{HR}=$
1.37; $95 \% \mathrm{Cl}=1.11,1.69$; unadjusted $P=0.0033$ ) higher risk of breast cancer relative to wild-type carriers, respectively. There was no individual association of the rs1801278 (G972R) SNP and risk. For the single IRS1 LD block, a similar, but nonsignificant $\mathrm{HR}$ of $1.52(95 \% \mathrm{Cl}=0.99,2.32$; unadjusted $P=0.055$ ) was observed in $B R C A 2$ carriers.

For IGF1, no significant associations were found for either $B R C A 1$ or BRCA2 carriers (Figure $3 b$ ).

\section{Insulin-like growth factor-1 receptor}

Figure 4 shows HR estimates for the 12 LD blocks genotyped in IGF1R. For BRCA1 carriers, significant associations were found between LD block 2 (SNP rs2715415) and LD block 11 and the risk of breast cancer diagnosis (unadjusted global $P$ values corresponding to a test of homogeneity of risk within the LD blocks were 0.011 for LD block 2 and 0.012 for LD block 11). While qualitatively consistent associations were also observed among BRCA2 carriers, they were not significant. After investigation in BRCA1 carriers of the individual SNPs within LD block 11 (Table 2), the only SNP that was significantly associated with risk was rs8038415 - in which individuals homozygous for the variant allele were estimated to 
Table 2

\begin{tabular}{|c|c|c|c|c|c|c|c|}
\hline & LD block ${ }^{a}$ & SNP & Genotype & $n$ & Hazard ratio & $\mathbf{9 5} \%$ confidence interval & $P$ for trend \\
\hline \multirow[t]{6}{*}{ IRS1 } & 1 & rs1801278 & $\mathrm{GG}$ & 990 & & & \\
\hline & & & $\mathrm{GA}, \mathrm{AA}$ & 115 & 0.82 & $0.58,1.17$ & \\
\hline & 1 & rs13306465 & GG & 999 & & & \\
\hline & & & $\mathrm{GA}, \mathrm{AA}$ & 97 & 1.44 & $1.07,1.94$ & \\
\hline & 1 & rs1801123 & AA & 823 & & & \\
\hline & & & AG, GG & 279 & 1.37 & $1.11,1.69$ & \\
\hline \multirow[t]{6}{*}{ IGF1R } & 11 & rs8038415 & $\mathrm{CC}$ & 281 & & & \\
\hline & & & CT & 536 & 1.11 & $0.88,1.41$ & \\
\hline & & & $\mathrm{TT}$ & 270 & 1.40 & $1.07,1.83$ & 0.015 \\
\hline & 11 & rs17847201 & GG & 350 & & & \\
\hline & & & GA & 581 & 0.87 & $0.69,1.10$ & \\
\hline & & & $\mathrm{AA}$ & 154 & 0.77 & $0.56,1.05$ & 0.091 \\
\hline
\end{tabular}

IRS1, insulin-like growth factor receptor substrate 1; IGF1R, insulin-like growth factor-1 receptor. aLinkage disequilibrium (LD) block was defined by pairwise LD coefficient $D^{\prime} \geq 0.90$.

experience a $40 \%$ higher risk of breast cancer diagnosis (unadjusted $P=0.014$, with $P$ for trend $=0.015$ ).

\section{Discussion}

The IGF pathway plays essential roles in regulating cell proliferation, differentiation, and apoptosis. It is a key factor in the development and progression of breast cancer, based on evidence from more than 1,100 published papers, ranging from in vivo and in vitro studies in humans and mice to epidemiologic studies (reviewed in [14-16]). This is the first study to investigate the role of genetic variants in IGF signaling as modifiers of breast cancer risk in women who carry deleterious mutations in BRCA1 and BRCA2. We investigated only a small number of the genes involved in IGF signaling. We found significant $\mathrm{HRs}$ associated with genetic variants in IGF1R and IRS1 in BRCA1 carriers, and in IGFBP2 in BRCA2 carriers. No other significant associations in the studied genes were identified.

There have been a limited number of epidemiologic studies of the association of sporadic breast cancer risk and genetic variation in genes in the IGF pathway. For IGF1, the primary ligand for the IGF1R, there have been inconsistent reports of associations with breast cancer risk with reports showing significant associations [28,29] and no associations [30-35]. The inconsistent results may be due to differences in genetic variants examined in the genes and/or in study design (for example, restriction to postmenopausal or premenopausal breast cancers). Several studies of SNPs in IGFBP1 reported no association with breast cancer, similar to what we observed for $B R C A 1$ and $B R C A 2$ mutation carriers $[28,35,36]$.
The IGFBPs serve as growth modulators, both independently and as regulators of IGFs [37-39]. IGFBP5 and IGFBP2 are overexpressed in breast cancer tissues [40,41], and are involved in apoptosis [42-44]. In a study of African Americans, with replication in Nigerians, we reported significant associations of SNPs within the IGFBP2 to IGFPB5 region and the risk of breast cancer [45]. These two genes are in a tail-to-tail configuration separated by only $10 \mathrm{~kb}$ on chromosome $2 \mathrm{q}$, so it is possible the same underlying causal variation results in an association with both genes. In the present study, we report a significant association of IGFBP2 SNP rs9341134, also observed in the previous study [45], and marginally significant associations with variants in IGFBP5. Resequencing is needed to try to identify the actual causal variant. Another piece of evidence that this region may be associated with breast cancer is the association of SNP rs13387042 with a 1.2 -fold increased risk in breast cancer, reported in a deCODE genome-wide association study [46] - with replication by the Cancer Genetic Markers of Susceptibility project (odds ratio $=1.2$ ) [47], by the Breast Cancer Association Consortium (odds ratio $=1.14$ ) [48], and by the Consortium of Investigators of Modifiers of BRCA1 and BRCA2 ( $\mathrm{HR}=$ 1.14 and $H R=1.18$ for $B R C A 1$ and $B R C A 2$ carriers, respectively) [49]. It is hypothesized that this SNP may act as a longrange regulatory element on expression of IGFBP2 or IGFBP5 [46].

Of the genes examined, only genetic variants in IGF1R and its adaptor protein IRS1 were associated with risk of breast cancer in BRCA1 carriers. IGF1R has both mitogenic and antiapoptotic roles in tumor development via signaling through the 


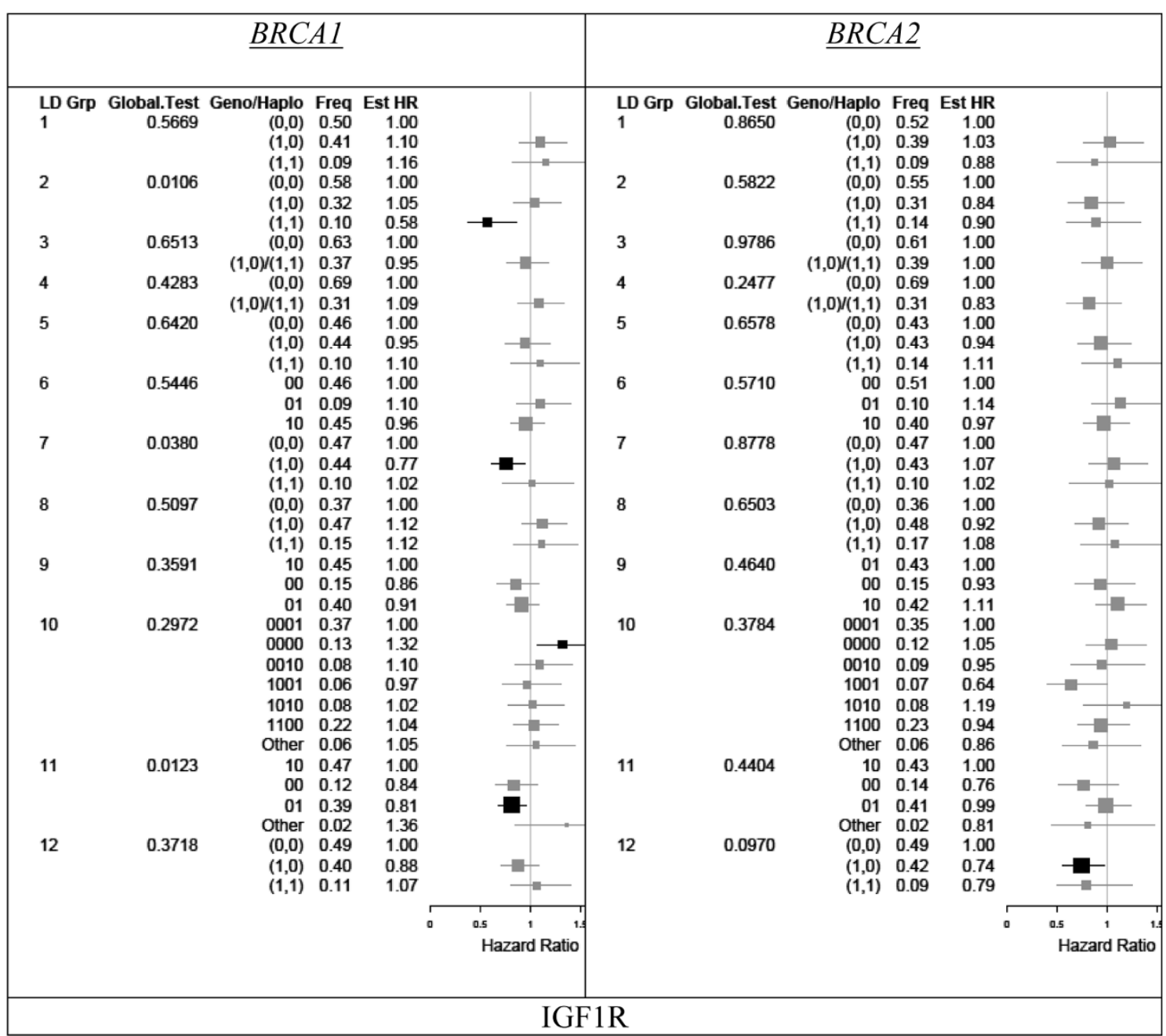

Haplotype presence for insulin-like growth factor-1 receptor. Estimated hazard ratios (Est HR) associated with haplotype presence for insulin-like growth factor-1 receptor (IGF1R). Linkage blocks were defined as in Figure 2 (pairwise linkage disequilibrium coefficient $D^{\prime} \geq 0.90$ ). Estimates were stratified by BRCA status (left column, BRCA1; right column, BRCA2) and adjusted for birth cohort and ethnicity as well as first pregnancy, prophylactic oophorectomy, and diagnosis of ovarian cancer as time-dependent covariates. LD Grp, linkage disequilibrium group; Geno/Haplo, genotype/ haplotype; Freq, frequency.

phosphatidylinositol-3-kinase and mitogen-activated protein kinase pathways [50], with its adaptor protein IRS1 critical in activating the downstream pathways. Both IGF1R overexpression and IRS1 overexpression have been associated with breast cancer development, and IGF1R is overexpressed in a majority of breast tumors [51]. Interestingly, BRCA1 directly affects IGF1 signaling. In multiple experimental systems including primary mammary tumors, cultured human cells, and Brca1-deficient mice, Shukla and colleagues showed that BRCA1 deficiency resulted in increased expression of IRS1, IGF1R and IGFBP2, and increased levels of serum IGF1 [19]. In another study investigating IGF1R levels in breast tumors, there were significantly higher levels of IGF1R in tumors from BRCA1 mutation carriers as compared with noncarriers [20].
In a series of experiments co-transfecting cell lines with IGF1R promoter constructs driving luciferase reporter genes, and a BRCA1 expression vector, it was shown that BRCA1 suppressed IGF1R promoter activity in a dose-dependent manner [52], through preventing binding of Sp1 to the IGF1R promoter, thus reducing transcription [52,53]. As demonstrated using western blots, wild-type BRCA1 was able to induce a large reduction in endogenous IGF1R levels [20]. In addition to its interaction with the IGF1R, BRCA1 interacts directly with the IRS1 promoter to inhibit its activity [19]. With induction of BRCA1, the authors observed a twofold and threefold decrease of IRS1 mRNA and protein levels, respectively, as well as a decrease in the phosphorylation level of AKT, a downstream target of IGF1R and IRS1 [19]. 
Based on these experiments, there is strong evidence that mutant forms of BRCA1 cause increased IGF1R activation, leading to a decrease in apoptosis and a concomitant increased survival of malignant cells, which then can proliferate. There is therefore a strong rationale for why genetic variation in IGF1R and IRS1 would be important in breast cancer risk in BRCA1 carriers. Experimental studies have not been published for BRCA2 to demonstrate whether there is a similar effect on transcriptional regulation.

As noted above, this is the first study to investigate the role of genetic variants in IGF signaling as modifiers of breast cancer risk in women who carry deleterious mutations in BRCA1 and $B R C A 2$. While the study does provide an important first step in identifying potential genetic modifiers of risk among $B R C A 1$ and BRCA2 carriers, it does suffer some limitations. First, although the IGF pathway was hypothesized a priori as a source for potential modifiers, multiple LD blocks were considered for association testing and such testing could lead to inflation of the overall type I error rate for the study. With this said, we only studied a small number of the genes in IGF signaling that we deemed a priori would potentially play a role in the time to diagnosis. Further, the goal of the current research was to generate hypotheses based upon the results from this well-defined set of genes, and it is our intention to further validate these results using an independent sample. As with all observational studies, there is the potential for selection bias and unmeasured confounding. We have, however, adjusted for those environmental factors that previous research has shown to most highly influence the risk of breast cancer diagnosis within this cohort, thus lowering the potential for unadjusted confounding.

We and others have investigated putative risk factors, and a number of published studies have implicated candidate genes (for example, AIB1 in BRCA1, RAD51 in BRCA2) and SNPs in FGFR2, MAP3K1, TNRC9, LSP1, and 2q35 previously identified from genome-wide association studies of breast cancer as modifiers of breast cancer or ovarian cancer penetrance in women who carry germline BRCA1 or BRCA2 mutations $[9-13,49]$. Our results suggest that variation in genes in IGF signaling also modify breast cancer penetrance in BRCA1 and $B R C A 2$ carriers.

\section{Conclusions}

The present study is the first to investigate the role of genetic variation in IGF signaling and breast cancer risk in women carrying deleterious mutations in BRCA1 and BRCA2. We identified significant associations for variants in IGF1R and IRS1 for $B R C A 1$ carriers and for variants in IGFBP2 for BRCA2 carriers. Given the known interaction of BRCA1 and IGF signaling, and specifically the regulation of IRS 1 and IGF1R by BRCA1, further replication and identification of causal mechanisms are needed to validate and better understand these associations.

\section{Competing interests}

The authors declare that they have no competing interests.

\section{Authors' contributions}

SLN designed and conceived of this work, was responsible for the genotyping and collection of all data, interpreted the results, and drafted and wrote the manuscript. SB was responsible for analysis of the data, interpreted the results, prepared tables and figures, and drafted and edited the manuscript. YCD was responsible for performing and overseeing the genotyping and quality control of the genotyping, and edited the manuscript. CFS, GP, HTL, KLN, TRR, JEG, FC, JW, SAN, PAG, MBD, AG, Cl, OIO, GT, WSR, NT, and JLB all provided the BRCA1 and BRCA2 mutation carriers, including samples and data, and reviewed and edited the manuscript. DLG was responsible for developing the statistical analysis and overseeing the programming and analysis of SB, interpreted the results, and drafted and wrote the manuscript. All authors read and approved the final manuscript.

\section{Additional files}

The following Additional files are available online:

\section{Additional file 1}

Word file containing a table that lists the LD blocks for the SNPs within each gene and the minor allele frequencies (MAF) for each SNP

See http://www.biomedcentral.com/content/ supplementary/bcr2414-S1.docx

\section{Acknowledgements}

The Modifiers and Genetics in Cancer Consortium includes the following centers and individuals: Baylor-Charles A. Sammons Cancer Center (Joanne L Blum, Becky Althaus, Gaby Ethington), Beth Israel Deaconess Medical Center (Nadine Tung), City of Hope National Medical Center (Veronica Lagos, Jeffery Weitzel), Creighton University (Carrie Snyder, Henry T Lynch, Patrice Watson), Dana Farber Cancer Institute (Kathryn Stoeckert, Judy E Garber), Northshore University Health System for Medical Genetics (Suzanne M O'Neill, Christina Selkirk, Wendy S Rubinstein), Fox Chase Cancer Center (Mary B Daly, Andrew K Godwin), Georgetown University (Claudine Isaacs), Jonsson Comprehensive Cancer Center at the University of California, Los Angeles (Joyce Seldon, Patricia A Ganz), Mayo Clinic College of Medicine (Linda Wadum, Fergus Couch), University of Chicago (Shelly Cummings, Olufunmilayo Olopade), University of California, Irvine (Susan L Neuhausen, Linda Steele), University of Pennsylvania Health System (Susan Domchek, Katherine Nathanson Tara Friebel, Timothy Rebbeck), University of Texas, San Antonio (Gail Tomlinson), University of Vienna (Christian Singer), and Women's College Hospital (Steven A Narod). This publication was supported in part by revenue from Nebraska cigarette taxes awarded to Creighton University by the Nebraska Department of Health and Human Services. The article's contents are solely the responsibility of the authors and do not necessarily represent the official views of the State of Nebraska or the Nebraska Department of Health and Human 
Services. Support was also received from NIH grants 5UO1 CA86389 (to HTL), R01-CA083855, R01-CA74415 (to SLN), R01-CA102776, R01-CA083855 (to TRR), P50CA83638, 5U01CA113916 (to AKG), and U01CA69631 (to MBD).

\section{References}

1. Antoniou A, Pharoah PD, Narod S, Risch HA, Eyfjord JE, Hopper $\mathrm{JL}$, Loman N, Olsson H, Johannsson O, Borg A, Pasini B, Radice $\mathrm{P}$, Manoukian S, Eccles DM, Tang N, Olah E, Anton-Culver $\mathrm{H}$, Warner E, Lubinski J, Gronwald J, Gorski B, Tulinius H, Thorlacius $\mathrm{S}$, Eerola H, Nevanlinna H, Syrjakoski K, Kallioniemi OP, Thompson $\mathrm{D}$, Evans $\mathrm{C}$, Peto J, et al.: Average risks of breast and ovarian cancer associated with BRCA1 or BRCA2 mutations detected in case series unselected for family history: a combined analysis of 22 studies. Am J Hum Genet 2003, 72:1117-1130.

2. Brose MS, Rebbeck TR, Calzone KA, Stopfer JE, Nathanson KL, Weber BL: Cancer risk estimates for BRCA1 mutation carriers identified in a risk evaluation program. J Nat/ Cancer Inst 2002, 94:1365-1372.

3. Easton DF, Bishop DT, Ford D, Crockford GP: Genetic linkage analysis in familial breast and ovarian cancer: results from 214 families. The Breast Cancer Linkage Consortium. Am J Hum Genet 1993, 52:678-701.

4. Risch HA, McLaughlin JR, Cole DE, Rosen B, Bradley L, Kwan E, Jack E, Vesprini DJ, Kuperstein G, Abrahamson JL, Fan I, Wong B, Narod SA: Prevalence and penetrance of germline BRCA1 and BRCA2 mutations in a population series of 649 women with ovarian cancer. Am J Hum Genet 2001, 68:700-710.

5. Struewing JP, Hartge P, Wacholder S, Baker SM, Berlin M, McAdams M, Timmerman MM, Brody LC, Tucker MA: The risk of cancer associated with specific mutations of BRCA1 and BRCA2 among Ashkenazi Jews. N Engl J Med 1997, 336:1401-1408.

6. Thorlacius S, Olafsdottir G, Tryggvadottir L, Neuhausen S, Jonasson JG, Tavtigian SV, Tulinius H, Ogmundsdottir HM, Eyfjord JE: A single BRCA2 mutation in male and female breast cancer families from Iceland with varied cancer phenotypes. Nat Genet 1996, 13:117-119.

7. Tonin P, Weber B, Offit K, Couch F, Rebbeck TR, Neuhausen S, Godwin AK, Daly M, Wagner-Costalos J, Berman D, Grana G, Fox E, Kane MF, Kolodner RD, Krainer M, Haber DA, Struewing JP, Warner E, Rosen B, Lerman C, Peshkin B, Norton L, Serova O, Foulkes WD, Lynch HT, Lenoir G, Narod S, Garber JE: Frequency of recurrent BRCA1 and BRCA2 mutations in Ashkenazi Jewish breast cancer families. Nat Med 1996, 2:1179-1183.

8. Ford D, Easton DF, Stratton M, Narod S, Goldgar D, Devilee P, Bishop DT, Weber B, Lenoir G, Chang-Claude J, Sobol H, Teare MD, Struewing J, Arason A, Scherneck S, Peto J, Rebbeck TR, Tonin P, Neuhausen S, Barkardottir R, Eyfjord J, Lynch H, Ponder BA, Gayther SA, Zelada-Hedman M, Consortium BCL: Genetic heterogeneity and penetrance analysis of the BRCA1 and BRCA2 genes in breast cancer families. The Breast Cancer Linkage Consortium. Am J Hum Genet 1998, 62:676-689.

9. Rebbeck TR, Kantoff PW, Krithivas K, Neuhausen S, Blackwood MA, Godwin AK, Daly MB, Narod SA, Garber JE, Lynch HT, Weber BL, Brown M: Modification of BRCA1-associated breast cancer risk by the polymorphic androgen-receptor CAG repeat. $\mathrm{Am} \mathrm{J}$ Hum Genet 1999, 64:1371-1377.

10. Rebbeck TR, Wang Y, Kantoff PW, Krithivas K, Neuhausen SL, Godwin AK, Daly MB, Narod SA, Brunet JS, Vesprini D, Garber JE, Lynch HT, Weber BL, Brown M: Modification of BRCA1- and BRCA2-associated breast cancer risk by AIB1 genotype and reproductive history. Cancer Res 2001, 61:5420-5424.

11. Wang WW, Spurdle AB, Kolachana P, Bove B, Modan B, Ebbers SM, Suthers G, Tucker MA, Kaufman DJ, Doody MM, Tarone RE, Daly M, Levavi H, Pierce H, Chetrit A, Yechezkel GH, ChenevixTrench G, Offit K, Godwin AK, Struewing JP: A single nucleotide polymorphism in the 5 ' untranslated region of RAD51 and risk of cancer among BRCA1/2 mutation carriers. Cancer Epidemiol Biomarkers Prev 2001, 10:955-960.

12. Antoniou AC, Sinilnikova OM, Simard J, Leone M, Dumont M, Neuhausen SL, Struewing JP, Stoppa-Lyonnet D, Barjhoux L, Hughes DJ, Coupier I, Belotti M, Lasset C, Bonadona V, Bignon YJ, Rebbeck TR, Wagner T, Lynch HT, Domchek SM, Nathanson KL, Garber JE, Weitzel J, Narod SA, Tomlinson G, Olopade OI, Godwin A, Isaacs C, Jakubowska A, Lubinski J, Gronwald J, et al:: RAD51
$135 \mathrm{G} \rightarrow \mathrm{C}$ modifies breast cancer risk among BRCA2 mutation carriers: results from a combined analysis of 19 studies. $\mathrm{Am} \mathrm{J}$ Hum Genet 2007, 81:1186-1200.

13. Antoniou AC, Spurdle AB, Sinilnikova OM, Healey S, Pooley KA, Schmutzler RK, Versmold B, Engel C, Meindl A, Arnold N, Hofmann W, Sutter C, Niederacher D, Deissler H, Caldes T, Kampjarvi K, Nevanlinna H, Simard J, Beesley J, Chen X, Neuhausen SL, Rebbeck TR, Wagner T, Lynch HT, Isaacs C, Weitzel J, Ganz PA, Daly MB, Tomlinson G, Olopade OI, et al.: Common breast cancerpredisposition alleles are associated with breast cancer risk in BRCA1 and BRCA2 mutation carriers. Am J Hum Genet 2008 , 82:937-948.

14. Sachdev D, Yee D: The IGF system and breast cancer. Endocr Relat Cancer 2001, 8:197-209.

15. Jerome L, Shiry L, Leyland-Jones B: Deregulation of the IGF axis in cancer: epidemiological evidence and potential therapeutic interventions. Endocr Relat Cancer 2003, 10:561-578.

16. Pollak MN, Schernhammer ES, Hankinson SE: Insulin-like growth factors and neoplasia. Nat Rev Cancer 2004 4:505-518.

17. Byrne C, Hankinson SE, Pollak M, Willett WC, Colditz GA, Speizer FE: Insulin-like growth factors and mammographic density. Growth Horm IGF Res 2000, 10(Suppl A):S24-S25.

18. Mitchell G, Antoniou AC, Warren R, Peock S, Brown J, Davies R, Mattison J, Cook M, Warsi I, Evans DG, Eccles D, Douglas F, Paterson J, Hodgson S, Izatt L, Cole T, Burgess L, Eeles R, Easton DF: Mammographic density and breast cancer risk in BRCA1 and BRCA2 mutation carriers. Cancer Res 2006, 66:1866-1872.

19. Shukla V, Coumoul X, Cao L, Wang RH, Xiao C, Xu X, Ando S, Yakar S, Leroith D, Deng C: Absence of the full-length breast cancer-associated gene-1 leads to increased expression of insulin-like growth factor signaling axis members. Cancer Res 2006, 66:7151-7157

20. Maor S, Yosepovich A, Papa MZ, Yarden RI, Mayer D, Friedman E, Werner $\mathrm{H}$ : Elevated insulin-like growth factor-I receptor (IGFIR) levels in primary breast tumors associated with BRCA1 mutations. Cancer Lett 2007, 257:236-243.

21. Stram DO, Haiman CA, Hirschhorn JN, Altshuler D, Kolonel LN, Henderson BE, Pike MC: Choosing haplotype-tagging SNPS based on unphased genotype data using a preliminary sample of unrelated subjects with an example from the Multiethnic Cohort Study. Hum Hered 2003, 55:27-36.

22. Environmental Genome Project [http://www.niehs.nih.gov/ research/supported/programs/egp/]

23. Follmann D, Proschan M, Leifer E: Multiple outputation: inference for complex clustered data by averaging analyses from independent data. Biometrics 2003, 59:420-429.

24. van Belle G, Heagerty PJ, Fisher LD, Lumley TS: Biostatistics: $A$ Methodology For the Health Sciences Wiley Series in Probability and Statistics; 2004. Wiley, Hoboken NJ USA.

25. Lin DY, Zeng D: Likelihood-based inference on haplotype effects in genetic association studies. J Am Stat Assoc 2006, 101:89-104.

26. French B, Lumley T, Monks SA, Rice KM, Hindorff LA, Reiner AP, Psaty BM: Simple estimates of haplotype relative risks in casecontrol data. Genet Epidemiol 2006, 30:485-494.

27. Lin DY, Wei $U$ : The robust inference for the cox proportional hazards model. J Am Stat Assoc 1989, 84:1074-1078.

28. Canzian F, McKay JD, Cleveland RJ, Dossus L, Biessy C, Rinaldi S Landi S, Boillot C, Monnier S, Chajes V, Clavel-Chapelon F, Tehard B, Chang-Claude J, Linseisen J, Lahmann PH, Pischon T, Trichopoulos D, Trichopoulou A, Zilis D, Palli D, Tumino R, Vineis $P$, Berrino $F$, Bueno-de-Mesquita $H B$, van Gils $C H$, Peeters $P H$, Pera G, Ardanaz E, Chirlaque MD, Quiros JR, et al:: Polymorphisms of genes coding for insulin-like growth factor 1 and its major binding proteins, circulating levels of IGF-I and IGFBP-3 and breast cancer risk: results from the EPIC study. $\mathrm{Br} J$ Cancer 2006, 94:299-307.

29. Cleveland RJ, Gammon MD, Edmiston SN, Teitelbaum SL, Britton JA, Terry MB, Eng SM, Neugut Al, Santella RM, Conway K: IGF1 CA repeat polymorphisms, lifestyle factors and breast cancer risk in the Long Island Breast Cancer Study Project. Carcinogenesis 2006, 27:758-765.

30. Al-Zahrani A, Sandhu MS, Luben RN, Thompson D, Baynes C, Pooley KA, Luccarini C, Munday $H$, Perkins B, Smith $P$, Pharoah PD, Wareham NJ, Easton DF, Ponder BA, Dunning AM: IGF1 and 
IGFBP3 tagging polymorphisms are associated with circulating levels of IGF1, IGFBP3 and risk of breast cancer. Hum Mol Genet 2006, 15:1-10.

31. Gonzalez-Zuloeta Ladd AM, Liu F, Houben MP, Arias Vasquez A, Siemes C, Janssens AC, Coebergh JW, Hofman A, Janssen JA, Stricker BH, van Duijn CM: IGF-1 CA repeat variant and breast cancer risk in postmenopausal women. Eur J Cancer 2007, 43:1718-1722.

32. Missmer SA, Haiman CA, Hunter DJ, Willett WC, Colditz GA, Speizer FE, Pollak MN, Hankinson SE: A sequence repeat in the insulin-like growth factor-1 gene and risk of breast cancer. Int $J$ Cancer 2002, 100:332-336.

33. Setiawan VW, Cheng I, Stram DO, Penney KL, Le Marchand L, Altshuler D, Kolonel LN, Hirschhorn J, Henderson BE, Freedman ML: Igf-I genetic variation and breast cancer: the multiethnic cohort. Cancer Epidemiol Biomarkers Prev 2006, 15:172-174.

34. Wagner K, Hemminki K, Israelsson E, Grzybowska E, Soderberg M, Pamula J, Pekala W, Zientek H, Mielzynska D, Siwinska E, Forsti A: Polymorphisms in the IGF-1 and IGFBP 3 promoter and the risk of breast cancer. Breast Cancer Res Treat 2005, 92:133-140.

35. Patel AV, Cheng I, Canzian F, Le Marchand L, Thun MJ, Berg CD, Buring J, Calle EE, Chanock S, Clavel-Chapelon F, Cox DG, Dorronsoro M, Dossus L, Haiman CA, Hankinson SE, Henderson BE, Hoover R, Hunter DJ, Kaaks R, Kolonel LN, Kraft P, Linseisen J, Lund E, Manjer J, McCarty C, Peeters PH, Pike MC, Pollak M, Riboli E, Stram DO, et al.: IGF-1, IGFBP-1, and IGFBP-3 polymorphisms predict circulating IGF levels but not breast cancer risk: findings from the Breast and Prostate Cancer Cohort Consortium (BPC3). PLOS ONE 2008, 3:e2578.

36. Cheng I, Penney KL, Stram DO, Le Marchand L, Giorgi E, Haiman CA, Kolonel LN, Pike M, Hirschhorn J, Henderson BE, Freedman ML: Haplotype-based association studies of IGFBP1 and IGFBP3 with prostate and breast cancer risk: the multiethnic cohort. Cancer Epidemiol Biomarkers Prev 2006, 15:1993-1997.

37. Belinsky MG, Rink L, Cai KQ, Ochs MF, Eisenberg B, Huang M, von Mehren M, Godwin AK: The insulin-like growth factor system as a potential therapeutic target in gastrointestinal stromal tumors. Cell Cycle 2008, 7:2949-2955.

38. Mohan S, Baylink D: IGF-binding proteins are multifunctional and act via IGF-dependent and -independent mechanisms. J Endocrinol 2002, 175:19-31.

39. Rosenzweig SA: What's new in the IGF-binding proteins? Growth Horm IGF Res 2004, 14:329-336.

40. Beattie J, Allan GJ, Lochrie JD, Flint DJ: Insulin-like growth factor-binding protein-5 (IGFBP-5): a critical member of the IGF axis. Biochem J 2006, 395:1-19.

41. So Al, Levitt RJ, Eigl B, Fazli L, Muramaki M, Leung S, Cheang MC, Nielsen TO, Gleave M, Pollak M: Insulin-like growth factor binding protein-2 is a novel therapeutic target associated with breast cancer. Clin Cancer Res 2008, 14:6944-6954.

42. Butt AJ, Dickson KA, McDougall F, Baxter RC: Insulin-like growth factor-binding protein- 5 inhibits the growth of human breast cancer cells in vitro and in vivo. J Biol Chem 2003, 278:29676-29685.

43. Butt AJ, Dickson KA, Jambazov S, Baxter RC: Enhancement of tumor necrosis factor-alpha-induced growth inhibition by insulin-like growth factor-binding protein-5 (IGFBP-5), but not IGFBP-3 in human breast cancer cells. Endocrinology 2005, 146:3113-3122.

44. Frommer KW, Reichenmiller K, Schutt BS, Hoeflich A, Ranke MB, Dodt G, Elmlinger MW: IGF-independent effects of IGFBP-2 on the human breast cancer cell line Hs578T. J Mol Endocrinol 2006, 37:13-23.

45. Garner CP, Ding YC, John EM, Ingles SA, Olopade OI, Huo D, Adebamowo C, Ogundiran T, Neuhausen SL: Genetic variation in IGFBP2 and IGFBP5 is associated with breast cancer in populations of African descent. Hum Genet 2008, 123:247-255.

46. Stacey SN, Manolescu A, Sulem P, Rafnar T, Gudmundsson J, Gudjonsson SA, Masson G, Jakobsdottir M, Thorlacius S, Helgason A, Aben KK, Strobbe LJ, Albers-Akkers MT, Swinkels DW, Henderson BE, Kolonel LN, Le Marchand L, Millastre E, Andres R, Godino J, Garcia-Prats MD, Polo E, Tres A, Mouy M, Saemundsdottir J, Backman VM, Gudmundsson L, Kristjansson K, Bergthorsson JT, Kostic J, et al.: Common variants on chromosomes 2q35 and $16 q 12$ confer susceptibility to estrogen receptor-positive breast cancer. Nat Genet 2007, 39:865-869.

47. Thomas $G$, Jacobs KB, Kraft $P$, Yeager M, Wacholder S, Cox DG, Hankinson SE, Hutchinson A, Wang Z, Yu K, Chatterjee N, GarciaClosas M, Gonzalez-Bosquet J, Prokunina-Olsson L, Orr N, Willett WC, Colditz GA, Ziegler RG, Berg CD, Buys SS, McCarty CA, Feigelson HS, Calle EE, Thun MJ, Diver R, Prentice R, Jackson R, Kooperberg C, Chlebowski R, Lissowska J, et al:: A multistage genome-wide association study in breast cancer identifies two new risk alleles at 1p11.2 and 14q24.1 (RAD51L1). Nat Genet 2009, 41:579-584

48. Milne RL, Benitez J, Nevanlinna H, Heikkinen T, Aittomaki $\mathrm{K}$, Blomqvist C, Arias Jl, Zamora MP, Burwinkel B, Bartram CR, Meindl A, Schmutzler RK, Cox A, Brock I, Elliott G, Reed MW, Southey MC, Smith L, Spurdle AB, Hopper JL, Couch FJ, Olson JE, Wang X, Fredericksen Z, Schurmann P, Bremer M, Hillemanns P, Dork T, Devilee P, van Asperen CJ, et al:: Risk of estrogen receptor-positive and -negative breast cancer and single-nucleotide polymorphism 2q35-rs13387042. J Natl Cancer Inst 2009, 101:1012-1018.

49. Antoniou AC, Sinilnikova OM, McGuffog L, Healey S, Nevanlinna $\mathrm{H}$, Heikkinen T, Simard J, Spurdle AB, Beesley J, Chen X, Neuhausen SL, Ding YC, Couch FJ, Wang X, Fredericksen Z, Peterlongo P, Peissel B, Bonanni B, Viel A, Bernard L, Radice P, Szabo Cl, Foretova L, Zikan M, Claes K, Greene MH, Mai PL, Rennert G, Lejbkowicz F, Andrulis IL, et al.: Common variants in LSP1, 2q35 and 8q24 and breast cancer risk for BRCA1 and BRCA2 mutation carriers. Hum Mol Genet 2009, 18:4442-4456.

50. $\mathrm{Yu} \mathrm{H}$, Rohan $\mathrm{T}$ : Role of the insulin-like growth factor family in cancer development and progression. J Nat/ Cancer Inst 2000, 92:1472-1489.

51. Cullen KJ, Yee D, Rosen N: Insulinlike growth factors in human malignancy. Cancer Invest 1991, 9:443-454.

52. Maor SB, Abramovitch S, Erdos MR, Brody LC, Werner H: BRCA1 suppresses insulin-like growth factor-I receptor promoter activity: potential interaction between BRCA1 and Sp1. Mol Genet Metab 2000, 69:130-136.

53. Abramovitch S, Glaser T, Ouchi T, Werner H: BRCA1-Sp1 interactions in transcriptional regulation of the IGF-IR gene. FEBS Lett 2003, 541:149-154. 